\title{
Factors associated with chronic and acute back pain in Wales, a cross-sectional study
}

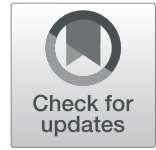

Steinthora Jonsdottir ${ }^{1}$, Haroon Ahmed ${ }^{2}$, Kristinn Tómasson ${ }^{1}$ and Ben Carter $^{3^{*}}$

\begin{abstract}
Background: Back pain is one of the most common causes for disability in the working population. Some risk factors for back pain are well known, however little is known about factors uniquely associated with acute or chronic back pain. This study aimed to elucidate patterns uniquely associated with acute or chronic back pain.

Methods: This study performed secondary analysis of data from the Welsh Health Survey 2012, a nationwide cross-sectional survey.

A multivariable analysis was carried out for risk factors found to be significantly associated with acute and chronic back pain.

Results: We found that increased BMI (aOR 1.20,95\% Cis 1.08, 1.33; BMI > 30), mental health score below average (aOR $1.59,95 \% \mathrm{Cls} 1.47,1.72)$, having a degree (aOR 1.28, 95\% Cls 1.12, 1.47) and being older than 24 years $(P<0.001)$ were associated with increased prevalence of acute back pain.

Higher prevalence of chronic back pain was seen in individuals characterised by increased deprivation (WIMD) (aOR 1.61, 95\% Cls 1.32, 1.96); increased age (aOR 7.34, 95\% Cls 5.25, 10.26; for 65+); being female (aOR =1.43, 95\% Cls 1.27, 1.61); lower educational attainment (aOR 0.44, 95\% Cls 0.36, 0.55) higher BMI (aOR=1.60 95\% Cls 1.38, 1.85; BMI > 30); poorer mental health score $(\mathrm{aOR}=3.1195 \% \mathrm{Cls} 2.76,3.51)$, and a sedentary lifestyle $(\mathrm{aOR}=0.58,95 \% \mathrm{Cls} 0.49,0.69 ; 3-5$ days of light exercise).
\end{abstract}

Conclusion: Increased deprivation, female gender, and little exercise were uniquely associated with chronic back pain. These characteristics may help clinicians to intervene to prevent acute backpain resulting in chronic cases.

Keywords: Chronic Back pain, Acute back pain, Risk factors, Physical activity, Prevention

\section{Background}

Back pain is a common and potentially disabling condition that can lead to reductions in quality of life, time off work and long-term disability. The Global Burden of Disease Study estimated the point prevalence of low back pain to be $9.4 \%$, and reported low back pain to be the condition responsible for the most years lived with disability [1]. Back pain is one of the most common causes for disability in the working population, and severely impacts upon work productivity and absenteeism [1]. In the UK alone, almost 3.4 million working days were lost due to work-related back pain in 2016/17, that is $13.3 \%$ of all working days lost due to ill health

\footnotetext{
* Correspondence: ben.carter@kcl.ac.uk

${ }^{3}$ Department of Biostatistics and Health Informatics, Institute of Psychiatry,

Psychology \& Neuroscience, King's College London, De Crespigny Park,

London SE5 8AF, UK

Full list of author information is available at the end of the article
}

[2]. Low back pain is the reason for one in every seven general practice consultations [3]. The associated health care cost and burden has been reported across health care systems worldwide $[4,5]$. Hong et al. [6] found that the healthcare costs of patients suffering chronic low back pain (CLBP) were double those of matched controls without CLBP.

\section{Chronic and acute back pain}

Back pain is defined as acute when it has persisted for up to 6 weeks and sub-acute when it has persisted for up to 3 months [7]. Chronic back pain is defined as back pain that is present for more than 3 months [8] and is associated with patients receiving treatment $[9,10]$. Acute back pain is often the result of actual or near tissue injury or sprain [7] and individuals with acute back pain are less likely to seek care or be referred for 
treatment $[9,10]$. Chronic pain often persists even though the initial injury has healed [7]. These cases are more likely to be referred for treatment than the more acute cases that are commonly left untreated $[9,10]$.

\section{Risk factors}

There is good evidence for an association between increasing age and obesity (BMI > 30) and risk of back pain $[4,11-21]$ and that obesity is a strong predictor of disability caused by back pain $[20,22,23]$. It is also known that the prevalence and severity of back pain is higher where there is greater deprivation [4, 12, 14-16, 19-21, 24-28]. There is conflicting evidence on the effect of physical activity (PA) on back pain. Heneweer et al. [13] suggested a U-shaped dose-response relationship between PA and back pain. Other studies have found that physical inactivity is associated with a significant increase in risk of back pain $[17,22]$. There is some evidence suggesting that females have a greater risk of back pain, [4, 11-21, 24] however a recent global study reported this varied by region [1].

There is limited evidence that job demands including lifting and twisting [13, 20, 26, 29]; ethnicity [18, 24]; genetic factors [14]; and mental health comorbidities $[4,14,22,26]$ are all associated with higher risk of back pain. The varying level of evidence, available literature and the lack of a standardised definition of back pain make definitive conclusions challenging [30, 31].

\section{Methods}

\section{Aim and objectives}

This study aimed to elucidate patterns uniquely associated with acute or chronic back pain. Differentiating between the two is challenging in clinical practice. Identifying risk factors associated with the pattern may help clinicians differentiate between the two conditions, manage them more appropriately and ultimately help to improve patient outcomes. In addition this could enable targeting of those at greatest risk for prevention through e.g. workplace modification strategies.

\section{Study design}

We used a population based cross-sectional survey (The Welsh Health Survey 2012). The survey collected information on health status, illnesses, lifestyle and health service use in the general population. The sampling frame includes $99 \%$ of all private households in Wales. A sample of 14,775 households were drawn, stratified by geographical area. To achieve the aim of at least 600 interviews per geographical area, a minimum of 575 households were sampled in each geographical area. Household data were collected by enumerator from each adult aged 16 years or older. Further details about collection of data can be found on the Welsh Health Survey 2013 (WHS) [32].

\section{Outcomes}

Primary outcomes in this study were:

a) Acute back pain (episodes of untreated backache in the last 12 months) $[9,10]$

b) Chronic back pain (Back pain currently being treated) $[9,10]$

For the purpose of this study back pain currently being treated was considered a measure of chronic back pain, and untreated backache in the last 12 months considered a measure of acute back pain.

\section{Covariates}

The following mechanistically plausible covariates were investigated for associations with back pain (acute, and chronic):

- Demographic: Age (age bands 16-24, 25-44, 45-64, 65+); Gender.

- Socioeconomic: Educational attainment (No qualification, other qualification, degree equivalent or above); Occupational status (Managerial and professional, intermediate, routine and manual, never worked/long term unemployed); Welsh index of multiple deprivation 2014 (WIMD) (Deprivation quintiles).

- Clinical: Mental health measured by the SF-36 (<50 vs. > 50); BMI (less than 18.5, 18.5-25, 25-30, 30 and over); Depression (treated vs. untreated); Anxiety (treated vs. untreated); Physical activity (PA) (meeting the UK PA guidelines vs. not meeting them and number of days of light, moderate or vigorous exercise per week).

\section{Data analysis}

An a priori statistical analysis plan was followed (available on request). Descriptive statistics tabulated demographic and risk factors, for acute and chronic back pain, and counts were presented. Crude logistic regression models were fitted to each risk factor and odds ratios (ORs) were presented with 95\% confidence intervals (95\% CI) and $P$-values. A multivariable logistic regression model with a forward stepping approach where a likelihood ratio test (LRT) of sequential nested models, was used to determine parsimonious independent associations with the covariates $(p<0.01)$. The final analyses were inclusive of all risk factors from either of the analyses. The analysis was adjusted for the clustered nature of the respondents within geographical areas within the UK, by estimating inflated standard errors using the 
robust cluster estimators of the variances. Stata 13 was used for all analyses.

\section{Results}

There were 19,282 eligible adults who were invited in the WHS 2013, and 15,007 were included in the analysis. The response rate was higher among women (83.1\%) than men (79.4\%), as well as among older individuals than younger individuals $(70.3 \%$ for $16-24$ years, $75.6 \%$ for $25-44$ years, $85.1 \%$ for $45-64$ years, $88.9 \%$ for 65 years and older). There was less than $5 \%$ missing data for any included variable.

The prevalence of acute back pain was $31.5 \%$ and the prevalence of chronic back pain was $13.4 \%$ (Table 1). The prevalence of reported acute and chronic back pain combined was $39.1 \%$.

\section{Acute back pain}

The crude analysis found that increased BMI (aOR 1.20, 95\% CIs 1.08, 1.33; BMI > 30), mental health score below average (aOR 1.59, 95\%CIs 1.47, 1.72; mental health score below avg), having a degree (aOR 1.28, 95\% CIs 1.12, 1.47; Degree or higher) and being older than 24 years $(P<$ 0.001 ) were associated with increased prevalence of acute back pain. In a multivariable analysis we found consistent results with the crude analysis (Table 2).

\section{Chronic back pain}

In the multivariable analysis higher rates of chronic back pain were seen in individuals who were characterised by increased deprivation (WIMD) (aOR 1.61, 95\% CIs 1.32, 1.96; most deprived); increased age (aOR 7.34, 95\% CIs $5.25,10.26$; for $65+$ ); being female $(\mathrm{aOR}=1.43,95 \% \mathrm{CIs}$ $1.27,1.61$ ); lower educational attainment (aOR 0.44, 95\% CIs 0.36, 0.55; degree or higher) higher $\mathrm{BMI}(\mathrm{aOR}=1.60$ $95 \%$ CIs 1.38, 1.85; BMI > 30); poorer mental health score $(\mathrm{aOR}=3.1195 \% \mathrm{CIs} 2.76,3.51$; below average $)$, and a sedentary lifestyle $(\mathrm{aOR}=0.58,95 \%$ CIs 0.49, 0.69; 3-5 days of light exercise) (Table 3).

In the crude analysis, all covariates were found predictive of chronic back pain. Increasing age and BMI were found to offer the greatest increase in odds of chronic back pain (Table 3 ).

\section{Discussion}

The study aimed to describe a pattern of acute and chronic back pain and examine possible risk factors in order to elucidate differences between the sub-types of back pain. We found that increasing age, higher BMI, better educational attainment and poorer mental health were independently associated with both acute and chronic back pain. However, we also found that increasing WIMD quintile (i.e., increasing deprivation), female gender, and exercising less than 2 days per week were uniquely associated with chronic back pain.

This is the first population-based study to compare independent associations for acute and chronic back pain. The strength was larger for all of the associations for chronic back pain and the associations showed a diluted effect in acute back pain in most of the covariates.

\section{Comparison with existing literature}

Educational attainment had the opposite effect on acute back pain compared to chronic back pain, and higher educational attainment was significantly associated with increased odds of acute back pain. Riskowski [33] reported a similar finding in a cross-sectional survey conducted in the U.S., in which they found that chronic back pain was more common in individuals of lower socioeconomic position and that acute back pain was more common in individuals of higher socioeconomic positions. Riskowski suggests that these unusual findings could be related to changes in socioeconomic positions over time as acute pain becomes chronic [33]. Assuming that untreated backache represents acute cases and treated back pain represents chronic cases similar suggestions might be made for this study, as educational attainment is an important marker for socioeconomic status and deprivation. Definitive explanations of these findings are difficult, although speculative suggestions can be made that cases of acute back pain in those with higher educational attainment are less likely to become chronic because of better knowledge of self-regulation or coping strategies in addition to this group having in general better means. This would result in most back pain cases in those with higher educational attainment being acute and not becoming chronic. We found obesity (BMI > 30) to be independently associated with chronic back pain, this is in line with previous studies [4, 11-21]. Fransen et al. (2002) found obesity to be a significant predictor of chronicity in individuals receiving compensation for working days lost due to acute back pain [34].

A recent systematic review found that stratified programmes were effective in preventing the development of chronic back pain. Those classified at low risk of developing chronic back pain benefited from simple educational messages while those classified at medium or high risk benefited from a combination of reactivation programmes, exercise and cognitive-behavioural interventions. We have identified factors independently associated with chronic back pain only. This may help to determine the risk of patients developing chronic back pain, and in turn determine a suitable prevention intervention [35].

Our findings in general are in line with previous studies however it is the first in the UK to distinguish between acute and chronic back pain. 
Table 1 Numbers and proportions of acute and chronic back pain across all covariates

\begin{tabular}{|c|c|c|c|c|c|c|}
\hline & Acute $b$ & & Chronic & ain & All back & \\
\hline & $\overline{\text { Total }}$ & Pain (\%) & Total & Pain (\%) & Total & Pain (\%) \\
\hline Total & 14,359 & $4519(31.5 \%)$ & 14,351 & $1772(13.4 \%)$ & 14,100 & $5520(39.1 \%)$ \\
\hline Deprivation (WIMD quintile) & 14,359 & & 14,351 & & 14,100 & \\
\hline Least deprived & 2839 & $892(31.42)$ & 2859 & $248(8.67)$ & 1029 & $1029,(36.65)$ \\
\hline 2 & 3065 & $994(32.43)$ & 3053 & $347(11.37)$ & 1207 & $1207,(40.07)$ \\
\hline 3 & 3275 & $1053(32.15)$ & 3309 & 409 (12.36) & 1275 & $1275,(47.05)$ \\
\hline 4 & 2762 & $866(31.35)$ & 2745 & 381 (13.88) & 1072 & $1072,(45.79)$ \\
\hline Most deprived & 2418 & $714(29.53)$ & 2385 & $387(16,23)$ & 2529 & $2529,(108.03)$ \\
\hline Age (years) & 14,359 & & 14,351 & & & \\
\hline $16-24$ & 1718 & $387(22.53)$ & 1752 & $46(2.63)$ & 410 & 410, (24.05) \\
\hline $25-44$ & 3830 & $1264(33.84)$ & 3879 & $275(7.09)$ & 1421 & $1421,(37.25)$ \\
\hline $45-64$ & 4963 & $1731(34.88)$ & 4974 & 709 (14.25) & 2144 & $2144,(43.76)$ \\
\hline $65+$ & 3848 & $1137(29.55)$ & 3746 & $742(19.81)$ & 1545 & $1545,(41.97)$ \\
\hline Gender & 14,359 & & 14,351 & & & \\
\hline Female & 7699 & $2480(32.21)$ & 7667 & $1084(14.14)$ & 3098 & $3098,(41.05)$ \\
\hline Male & 6660 & $2039(30.62)$ & 6684 & $688(10.29)$ & 2422 & 2422, (36.96) \\
\hline Educational attainment & 13,398 & & 13,424 & & & \\
\hline No qualification & 2643 & $752(28.45)$ & 2573 & $573(22.27)$ & 1077 & $1077,(42.27)$ \\
\hline Other qualification & 8367 & $2731(32.64)$ & 8443 & $883(10.46)$ & 3231 & $3231,(39.01)$ \\
\hline Degree Equivalent and above & 2388 & $774(32.41)$ & 2408 & $136(5.65)$ & 856 & 856, (36.03) \\
\hline Occupational status (NS-SEC) & 13,959 & & 13,936 & & & \\
\hline Managerial and Professional occupations & 5170 & $1605(31.04)$ & 5228 & $461(8.82)$ & 1868 & $1868,(36.52)$ \\
\hline Intermediate occupations & 2853 & 964 (33.79) & 2834 & $330(11.64)$ & 1143 & $1143,(40.88)$ \\
\hline Routine and manual occupations & 5569 & $1718(30.85)$ & 5524 & $883(15.98)$ & 2217 & 2217, (40.74) \\
\hline Never worked and long-term unemployed & 357 & $104(29.13)$ & 350 & $65(18.57)$ & 143 & 143, (41.81) \\
\hline$B M l^{a}$ & 13,387 & & 13,391 & & & \\
\hline Less than 18.5 & 281 & $59(21.00)$ & 284 & $21(7.39)$ & 71 & $71,(26.01)$ \\
\hline 18.5 to under 25 & 5176 & $1498(28.94)$ & 5213 & $490(9.40)$ & 1778 & $1778,(34.88)$ \\
\hline 25 to under 30 & 4878 & $1604(32.88)$ & 4873 & 594 (12.19) & 1943 & 1943, (40.45) \\
\hline 30 and over & 3052 & $1073(35.16)$ & 3021 & $550(18.21)$ & 1386 & $1386,(46.31)$ \\
\hline Mental Health (SF-36 mental health score) & 14,359 & & 14,351 & & & \\
\hline Higher than average $(>50)^{\mathrm{b}}$ & 8803 & $2421(27.50)$ & 8862 & $632(7.13)$ & 2783 & $2783,(32.15)$ \\
\hline Lower than average $(<50)^{c}$ & 5556 & $2098(37.76)$ & 5489 & $1140(20.77)$ & 2737 & $2737,(50.28)$ \\
\hline Depression & 13,840 & & 14,165 & & & \\
\hline Yes & 1257 & $488(38.82)$ & 1183 & $403(34.07)$ & 717 & $717,(59.7)$ \\
\hline No & 12,583 & $3832(30.45)$ & 12,982 & $1204(9.27)$ & 4519 & $4519,(35.85)$ \\
\hline Anxiety & 13,776 & & 14,124 & & & \\
\hline Yes & 1025 & $392(38.24)$ & 959 & 315 (32.85) & 568 & 568, (58.32) \\
\hline No & 12,751 & $3904(30.62)$ & 13,156 & $1252(9.52)$ & 4624 & $4624,(36.16)$ \\
\hline Exercise & 14,136 & & 14,139 & & & \\
\hline Meeting PA guidelines $^{d}$ & 4106 & $1291(31.44)$ & 4156 & $269(6.47)$ & 1432 & $1432,(35.33)$ \\
\hline Not meeting guidelines & 10,030 & $3164(31.55)$ & 9983 & $1451(14.53)$ & 4001 & 4001, (40.64) \\
\hline
\end{tabular}

${ }^{\mathrm{a}}$ Body mass index

${ }^{\mathrm{b}}$ Mental health score above the average of the general population

${ }^{c}$ Mental health score below the average of the general population

${ }^{d}$ Meeting physical activity guidelines of 30 min of light to moderate exercise on at least 5 days of the week 
Table 2 Univariable logistic regression of acute back pain and multivariable logistic regression of acute back pain, adjusted for significantly associated covariates

\begin{tabular}{|c|c|c|c|c|c|}
\hline & Univaria & & & Multivariable analysis & \\
\hline & $\mathrm{N}$ & Crude OR (95\% CI) & $P$ value & Adjusted OR (95\% Cl) & $P$ value \\
\hline WIMD 2014 quintile & 14,359 & & & & \\
\hline Least deprived & & Reference category & & & \\
\hline 2 & & $1.05(0.94,1.17)$ & 0.405 & $1.03(0.92,1.16)$ & 0.611 \\
\hline 3 & & $1.03(0.93,1.15)$ & 0.539 & $1.00(0.89,1.13)$ & 0.940 \\
\hline 4 & & $1.00(0.89,1.12)$ & 0.958 & $0.93(0.82,1.05)$ & 0.261 \\
\hline Most deprived & & $0.91(0.81,1.03)$ & 0.138 & $0.86(0.76,0.98)$ & 0.029 \\
\hline Age & 14,359 & & & & \\
\hline $16-24$ & & Reference category & & & \\
\hline $25-44$ & & $1.69(1.49,1.93)$ & $<0.001$ & $1.64(1.42,1.90)$ & $<0.001$ \\
\hline $45-64$ & & $1.84(1.62,2.09)$ & $<0.001$ & $1.73(1.50,1.99)$ & $<0.001$ \\
\hline $65+$ & & $1.44(1.26,1.65)$ & $<0.001$ & $1.49(1.27,1.73)$ & $<0.001$ \\
\hline Gender & 14,359 & & & & \\
\hline Male & & Reference category & & & \\
\hline Female & & $1.08(1.00,1.16)$ & 0.040 & $1.01(0.94,1.10)$ & 0.761 \\
\hline Educational attainment & 13,398 & & & & \\
\hline No qualification & & Reference category & & & \\
\hline Degree equivalent or higher & & $1.21(1.07,1.36)$ & 0.002 & $1.28(1.12,1.47)$ & $<0.001$ \\
\hline Other qualifications & & $1.22(1.11,1.34)$ & $<0.001$ & $1.32(1.18,1.47)$ & $<0.001$ \\
\hline$B M l^{\mathrm{a}}$ & 13,387 & & & & \\
\hline Less than 18.5 & & $0.65(0.49,0.87)$ & 0.004 & $0.79(0.58,1.07)$ & 0.127 \\
\hline 18.5 to under 25 & & Reference category & & & \\
\hline 25 to under 30 & & $1.20(1.11,1.31)$ & $<0.001$ & $1.14(1.04,1.25)$ & 0.004 \\
\hline 30 and over & & $1.33(1.21,1.46)$ & $<0.001$ & $1.20(1.08,1.33)$ & 0.001 \\
\hline Mental health (SF-36) & 14,359 & & & & \\
\hline Above average ${ }^{b}$ & & Reference category & & & \\
\hline Below average $e^{c}$ & & $1.60(1.49,1.72)$ & $<0.001$ & $1.59(1.47,1.72)$ & $<0.001$ \\
\hline Vigorous exercise & 13,757 & & & & \\
\hline $0-2$ days per week & & Reference category & & & \\
\hline $3-5$ days & & $0.83(0.73,0.94)$ & 0.03 & $0.91(0.80,1.03)$ & 0.156 \\
\hline 6-7 days & & $0.83(0.68,1.02)$ & 0.077 & $0.91(0.74,1.13)$ & 0.406 \\
\hline
\end{tabular}

aody mass index

${ }^{\mathrm{b}}$ Mental health score above the average of the general population

${ }^{c} M e n t a l$ health score below the average of the general population

\section{Strengths and limitations}

This is the first population-based study of back pain in the UK, and the first to differentiate between acute and chronic back pain. The reported results cannot infer causality due to the nature of the study design. Multivariable analyses controlled for known confounders, however this doesn't include the unknown confounders, i.e. work demands, chronic stress and genetic factors. There is a limitation in the measures for chronic and acute back pain used in this study. The evidence suggests that treated cases are likely to represent chronic cases and untreated cases are likely to represent acute cases $[9,10]$. However, we anticipate that some cases may be misclassified, as acute back pain may sometimes be treated with for example, anti-inflammatories.

There is debate over these definitions and this is unlikely to be universal. Potential biases affecting the study include selection bias and reporting bias. We cannot ignore the possibility of reverse causality. Given the weaknesses, caution is needed when interpreting these findings, however, this study gives a clue about the difference in risk factors between acute and chronic back pain. 
Table 3 Univariable logistic regression of chronic back pain and multivariable logistic regression of chronic back pain, adjusted for significantly associated covariates

\begin{tabular}{|c|c|c|c|c|c|}
\hline & Univaria & lysis & & Multivariable analysis & \\
\hline & $\mathrm{N}$ & Crude OR (95\% Cl) & $P$ value & Adjusted OR (95\% Cl) & $P$ value \\
\hline WIMD 2014 quintile & 14,351 & & & & \\
\hline Least deprived & & - & - & - & - \\
\hline 2 & & $1.35(1.14,1.60)$ & 0.001 & $1.32(1.09,1.60)$ & 0.005 \\
\hline 3 & & $1.48(1.26,1.75)$ & $<0.001$ & $1.33(1.10,1.61)$ & 0.003 \\
\hline 4 & & $1.70(1.43,2.01)$ & $<0.001$ & $1.42(1.16,1.72)$ & $<0.001$ \\
\hline Most deprived & & $2.04(1.72,2.42)$ & $<0.001$ & $1.61(1.32,1.96)$ & $<0.001$ \\
\hline Age & 14,351 & & & & \\
\hline $16-24$ & & - & - & - & - \\
\hline $25-44$ & & $2.83(2.06,3.89)$ & $<0.001$ & $2.42(1.71,3.42)$ & $<0.001$ \\
\hline $45-64$ & & $6.17(4.55,8.35)$ & $<0.001$ & $5.14(3.69,7.15)$ & $<0.001$ \\
\hline $65+$ & & $9.16(6.76,12.41)$ & $<0.001$ & $7.34(5.25,10.26)$ & $<0.001$ \\
\hline Gender & 14,351 & & & & \\
\hline Male & & - & - & - & - \\
\hline Female & & $1.44(1.30,1.59)$ & $<0.001$ & $1.43(1.27,1.61)$ & $<0.001$ \\
\hline Educational attainment & 13,424 & & & & \\
\hline No qualification & & - & - & - & - \\
\hline Degree equivalent or higher & & $0.21(0.17,0.25)$ & $<0.001$ & $0.44(0.36,0.55)$ & $<0.001$ \\
\hline Other qualifications & & $0.41(0.36,0.46)$ & $<0.001$ & $0.75(0.65,0.86)$ & $<0.001$ \\
\hline $\mathrm{BMI}^{\mathrm{a}}$ & 13,391 & & & & \\
\hline Less than 18.5- Underweight & & $0.77(0.49,1.21)$ & 0.258 & $0.91(0.55,1.48)$ & 0.699 \\
\hline 18.5 to under 25 - Normal weight & & - & - & - & - \\
\hline 25 to under 30- Overweight & & $1.34(1.18,1.52)$ & $<0.001$ & $1.20(1.04,1.38)$ & 0.013 \\
\hline 30 and over- Obese & & $2.15(1.88,2.45)$ & $<0.001$ & $1.60(1.38,1.85)$ & $<0.001$ \\
\hline Mental health (SF-36) & 14,351 & & & & \\
\hline Above average $^{b}$ & & - & - & - & - \\
\hline Below average ${ }^{c}$ & & $3.41(3.08,3.79)$ & $<0.001$ & $3.11(2.76,3.51)$ & $<0.001$ \\
\hline Light exercise & 14,014 & & & & \\
\hline $0-2$ days per week & & - & - & - & - \\
\hline $3-5$ days & & $0.43(0.37,0.49)$ & $<0.001$ & $0.58(0.49,0.69)$ & $<0.001$ \\
\hline 6-7 days & & $0.39(0.35,0.43)$ & $<0.001$ & $0.55(0.48,0.63)$ & $<0.001$ \\
\hline
\end{tabular}

${ }^{\mathrm{a}}$ Body mass index

${ }^{\mathrm{b}}$ Mental health score above the average of the general population

${ }^{c} M e n t a l$ health score below the average of the general population

\section{Conclusion}

Chronic back pain is a considerable public health concern and risk factors for acute and chronic back pain are different. This study has identified factors associated with chronic back pain that are not associated with acute back pain. This information may help clinicians to intervene to prevent acute back pain resulting in chronic cases. More emphasis should be put on service for those in deprived areas. In addition this information can help target groups and individuals for preventive measures.
Longitudinal cohort studies are needed to make conclusions about causality regarding risk factors of back pain and to distinguish successfully between cases that progress form acute to chronic. In addition further analysis of long-term cohort studies are needed to investigate the effect of light exercise on chronic back pain as a suggested means of self-management.

\section{Abbreviations}

aOR: adjusted Odds Ratio; BMI: Body mass index; CLBP: Chronic low back pain; LRT: Likelihood ratio test; OR: Odds Ratio; PA: Physical activity; WHS: Welsh health survey; WIMD: Welsh Index of Multiple Deprivation 


\section{Acknowledgements}

The authors would like to thank the team at the Health statistics and analysis unit, Welsh Government, who provided the data used in this analysis.

\section{Funding}

We acknowledge the support of the National Institute for Health Research (NIHR) Biomedical Research Centre at South London and Maudsley NHS Foundation Trust and King's College London (B. C.). The funding bodies were not party to any part of the research, analysis, interpretation, or dissemination.

\section{Availability of data and materials}

The data that support the findings of this study are available from The Welsh Government (The Welsh Health Survey) but restrictions apply to the availability of these data, which were used under license for the current study, and so are not publicly available. Data are however available from the authors upon reasonable request and with permission of Welsh government.

\section{Authors' contributions}

SJ and BC carried out the data collection and analysis and were major contributors in writing the manuscript. KT and HA were contributors in writing and reviewing the manuscript and all authors read and approved the final manuscript.

\section{Ethics approval and consent to participate}

The data used in this study was obtained from a cross-sectional nationwide survey and data were anonymised. Ethical approval was included in Welsh Health Survey, and a local ethics committee ruled that participants were not required to be additionally consented for this study.

\section{Consent for publication}

Not applicable.

\section{Competing interests}

The authors declare that they have no competing interests.

\section{Publisher's Note}

Springer Nature remains neutral with regard to jurisdictional claims in published maps and institutional affiliations.

\section{Author details}

${ }^{1}$ Administration of Occupational Safety and Health, Dvergshofdi 2, 110 Reykjavik, Iceland. ${ }^{2}$ Division of Population Medicine, Cardiff University School of Medicine, Heath Park, Cardiff CF14 4YS, UK. ${ }^{3}$ Department of Biostatistics and Health Informatics, Institute of Psychiatry, Psychology \& Neuroscience, King's College London, De Crespigny Park, London SE5 8AF, UK.

Received: 16 July 2018 Accepted: 25 February 2019

Published online: 15 May 2019

\section{References}

1. Hoy D, March L, Brooks P, Blyth F, Woolf A, Bain C, et al. The global burden of low back pain: estimates from the global burden of disease 2010 study. Ann Rheum Dis. 2014;73(6):968-74.

2. Work-related Musculoskeletal Disorders (WRMSDs) Statistics in Great Britain 2017 [Internet]. 2017. Available from: www.hse.gov.uk/statistics/. Accessed 20 Feb 2018.

3. Jordan KP, Kadam UT, Hayward R, Porcheret M, Young C, Croft P. Annual consultation prevalence of regional musculoskeletal problems in primary care: an observational study. BMC Musculoskelet Disord. 2010;11:144.

4. Langley PC. The prevalence, correlates and treatment of pain in the European Union. Curr Med Res Opin. 2011;27(2):463-80.

5. Dagenais S, Caro J, Haldeman S. A systematic review of low back pain cost of illness studies in the United States and internationally. Spine J. 2008;8:8-20.

6. Hong J, Reed C, Novick D, Happich M. Costs associated with treatment of chronic low back pain: an analysis of the UK general practice research database. Spine (Phila Pa 1976). 2013:38(1):75-82.

7. Goodwin J, Bajwa ZH. Understanding the patient with chronic pain. In: Warfield CA, Bajwa ZH, editors. Principles \& Practice of Pain Medicine, 2nd Edition. New York: McGraw-Hill; 2004. ISBN: 0-07-144349-5
8. van Tulder M, Becker A, Bekkering T, Breen A, del Real MTG, Hutchinson A et al. Chapter 3 European guidelines for the management of acute nonspecific low back pain in primary care. Eur Spine J. 2006;15(Suppl 2): 169-91.

9. Ferreira ML, Machado G, Latimer J, Maher C, Ferreira PH, Smeets RJ. Factors defining care-seeking in low back pain - a meta-analysis of population based surveys. Eur J Pain. 2010;14(7):747.e1-7.

10. Fischbein R, McCormick K, Selius BA, Labuda Schrop S, Hewit M, Baughman $K$, et al. The assessment and treatment of back and neck pain: an initial investigation in a primary care practice-based research network. Prim Heal Care Res Dev. 2015;16(5):461-9.

11. Breivik H, Collett B, Ventafridda V, Cohen R, Gallacher D. Survey of chronic pain in Europe: prevalence, impact on daily life, and treatment. Eur J Pain. 2006;10(4):287-333.

12. Volkers AC, Westert GP, Schellevis FG. Health disparities by occupation, modified by education: a cross-sectional population study. BMC Public Health. 2007;7:196.

13. Heneweer $H$, Vanhees $L$, Picavet $H$. Physical activity and low back pain: a U-shaped relation? Pain. 2009;143(1-2):21-5.

14. van Hecke O, Torrance N, Smith BH. Chronic pain epidemiology and its clinical relevance. Br J Anaesth. 2013;111(1):13-18.

15. Bergman S, Herrstrom P, Hogstrom K, Petersson IF, Svensson B, Jacobsson LT. Chronic musculoskeletal pain, prevalence rates, and sociodemographic associations in a Swedish population study. J Rheumatol. 2001;28:1369-77.

16. Dorner TE, Muckenhuber J, Stronegger WJ, Rsky É, Gustorff B, Freidl W. The impact of socio-economic status on pain and the perception of disability due to pain. Eur J Pain. 2011;15(1):103-9.

17. Jhun HJ, Park JY. Estimated number of Korean adults with back pain and population-based associated factors of back pain: data from the fourth Korea National Health and nutrition examination survey. J Korean Neurosurg Soc. 2009;46(5):443-50.

18. Johannes CB, Le TK, Zhou X, Johnston JA, Dworkin RH. The prevalence of chronic pain in United States adults: results of an internet-based survey. J Pain. 2010;11(11):1230-9.

19. Latza U, Kohlmann T, Deck R, Raspe H. Can health care utilization explain the association between socioeconomic status and back pain? Spine (Phila Pa 1976). 2004;29(14):1561-6.

20. Leclerc A, Gourmelen J, Chastang J-F, Plouvier S, Niedhammer I, Lanoë J-L. Level of education and back pain in France: the role of demographic, lifestyle and physical work factors. Int Arch Occup Environ Health. 2009; 82(5):643-52.

21. Schmidt CO, Raspe H, Pfingsten M, Hasenbring M, Basler HD, Eich W, et al. Back pain in the German adult population: prevalence, severity, and sociodemographic correlates in a multiregional survey. Spine (Phila Pa 1976). 2007;32(18):2005-11.

22. Leino-Arjas $P$, Hänninen $K$, Puska P. Socioeconomic variation in back and joint pain in Finland. Eur J Epidemiol. 1998;14(1):79-87.

23. Tokuda Y, Ohde S, Takahashi O, Shakudo M, Yanai H, Shimbo T, et al. Musculoskeletal pain in Japan: prospective health diary study. Rheumatol Int. 2007;28(1):7-14.

24. Webb R, Brammah T, Lunt M, Urwin M, Allison T, Symmons D. Prevalence and predictors of intense, chronic, and disabling neck and back pain in the UK general population. Spine (Phila Pa 1976). 2003;28(11):1195-202.

25. JL C, JA M. The impact of social deprivation on chronic back pain outcomes. Chronic IIIn. 2005;1(2):121-9.

26. Moffett JA, Underwood MR, Gardiner ED. Socioeconomic status predicts functional disability in patients participating in a back pain trial. Disabil Rehabil. 2009;31(10):783-90.

27. Hagen $\mathrm{KB}$, Holte $\mathrm{HH}$, Tambs K, Bjerkedal T. Socioeconomic factors and disability retirement from back pain. A 1983-1993 population-based prospective study in Norway. Spine (Phila Pa 1976). 2000;25(19):2480-7.

28. Hagen K, Zwart JA, Svebak S, Bovim G, Jacob Stovner L. Low socioeconomic status is associated with chronic musculoskeletal complaints among 46,901 adults in Norway. Scand J Public Heal. 2005;33(4):268-75.

29. Picavet HSJ, Schuit AJ. Physical inactivity: a risk factor for low back pain in the general population? J Epidemiol Community Health. 2003;57(7):517-8,

30. Sitthipornvorakul E, Janwantanakul P, Purepong N, Pensri P, van der Beek AJ. The association between physical activity and neck and low back pain: a systematic review. Eur Spine J. 2010;20(5):677-89.

31. Rossignol M, Rozenberg S, Leclerc A. Epidemiology of low back pain: What's new? Joint Bone Spine. 2009;76:608-13. 
32. Sadler K, Doyle M, Hussey D, Stafford R. Welsh Health survey 2012: technical report [internet]. 2013. Available from: http://doc.ukdataservice.ac.uk/doc/ 7459/mrdoc/pdf/7459_technical_report.pdf. Accessed 3 July 2015.

33. Riskowski JL. Associations of socioeconomic position and pain prevalence in the United States: findings from the National Health and nutrition examination survey. Pain Med. 2014;15(9):1508-21.

34. Fransen M, Woodward M, Norton R, Coggan C, Dawe M, Sheridan N. Risk factors associated with the transition from acute to chronic occupational back pain. Spine. 2002;27(1):92-8.

35. Meyer C, Denis CM, Berguin AD. Secondary prevention of chronic musculoskeletal pain: a systematic review of clinical trials. Ann Phys Rehabil Med. 2018;61(5):323-38.

Ready to submit your research? Choose BMC and benefit from:

- fast, convenient online submission

- thorough peer review by experienced researchers in your field

- rapid publication on acceptance

- support for research data, including large and complex data types

- gold Open Access which fosters wider collaboration and increased citations

- maximum visibility for your research: over $100 \mathrm{M}$ website views per year

At BMC, research is always in progress.

Learn more biomedcentral.com/submissions 